\title{
Outcomes of patients admitted to intensive care units for acute manifestation of small-vessel vasculitis: a multicenter, retrospective study
}

Antoine Kimmoun ${ }^{1,2+}$ (D) Elisabeth Baux ${ }^{1,2 \dagger}$, Vincent Das ${ }^{3}$, Nicolas Terzi ${ }^{4}$, Patrice Talec ${ }^{5}$, Pierre Asfar ${ }^{5}$, Stephan Ehrmann ${ }^{6}$, Guillaume Geri ${ }^{7}$, Steven Grange ${ }^{8}$, Nadia Anguel $^{9}$, Alexandre Demoule ${ }^{10}$,

Anne Sophie Moreau ${ }^{11}$, Elie Azoulay ${ }^{12}$, Jean-Pierre Quenot ${ }^{13}$, Julie Boisramé-Helms ${ }^{14}$, Guillaume Louis ${ }^{15}$, Romain Sonneville ${ }^{16}$, Nicolas Girerd ${ }^{17}$, Nicolas Ducrocq ${ }^{1,2}$, Nelly Agrinier ${ }^{18}$, Denis Wahl ${ }^{19}$, Xavier Puéchal ${ }^{20}$ and Bruno Levy ${ }^{1,2^{*}}$

\begin{abstract}
Background: The outcomes of patients admitted to the intensive care unit (ICU) for acute manifestation of small-vessel vasculitis are poorly reported. The aim of the present study was to determine the mortality rate and prognostic factors of patients admitted to the ICU for acute small-vessel vasculitis.

Methods: This retrospective, multicenter study was conducted from January 2001 to December 2014 in 20 ICUs in France. Patients were identified from computerized registers of each hospital using the International Classification of Diseases, Ninth Revision (ICD-9). Inclusion criteria were (1) known or highly suspected granulomatosis with polyangiitis, eosinophilic granulomatosis with polyangiitis, microscopic polyangiitis (respectively, ICD-9 codes M31.3, M30.1, and M31.7), or anti-glomerular basement membrane antibody disease (ICD-9 codes N08.5X-005 or M31.0+); (2) admission to the ICU for the management of an acute manifestation of vasculitis; and (3) administration of a cyclophosphamide pulse in the ICU or within $48 \mathrm{~h}$ before admission to the ICU. The primary endpoint was assessment of mortality rate 90 days after admission to the ICU.

Results: Eighty-two patients at 20 centers were included, $94 \%$ of whom had a recent ( $<6$ months) diagnosis of small-vessel vasculitis. Forty-four patients (54\%) had granulomatosis with polyangiitis. The main reasons for admission were respiratory failure (34\%) and pulmonary-renal syndrome (33\%). Mechanical ventilation was required in $51 \%$ of patients, catecholamines in $31 \%$, and renal replacement therapy in $71 \%$. Overall mortality at 90 days was $18 \%$ and the mortality in ICU was $16 \%$. The main causes of death in the ICU were disease flare in $69 \%$ and infection in $31 \%$. In univariable analysis, relevant factors associated with death in nonsurvivors compared with survivors were Simplified Acute Physiology Score II (median [interquartile range] 51 [38-82] vs. 36 [27-42], $p=0.005$ ), age (67 years [62-74] vs. 58 years [40-68], $p<0.003$ ), Sequential Organ Failure Assessment score on the day of cyclophosphamide administration (11 [6-12] vs. 6 [3-7], $p=0.0004$ ), and delayed administration of cyclophosphamide (5 days [3-14] vs. 2 days $[1-5], p=0.0053)$.

(Continued on next page)
\end{abstract}

\footnotetext{
* Correspondence: b.levy@chru-nancy.fr

${ }^{\dagger}$ Equal contributors

'Brabois Medical Intensive Care Unit, Nancy University Hospital, Vandoeuvre-les-Nancy, Nancy 54000, France

${ }^{2}$ INSERM U1116, Vandoeuvre-les-Nancy, Nancy, France

Full list of author information is available at the end of the article
} 
(Continued from previous page)

Conclusions: Patients admitted to the ICU for management of acute small-vessel vasculitis benefit from early, aggressive intensive care treatment, associated with an $18 \%$ death rate at 90 days.

Keywords: Intensive care unit, Small-vessel vasculitis, Outcome

\section{Background}

The revised International Chapel Hill Consensus Conference Nomenclature of Vasculitides [1] characterizes vasculitis as a function of the size of the vessel involved. According to this nomenclature, small-vessel vasculitides (SVV) are a group of diseases that includes antineutrophil cytoplasmic antibody-associated vasculitis (AAV) and immune complex SVV. Epidemiological data on SVV remain scarce, although they could be considered as orphan diseases [2]. With the development of therapeutic strategies that include corticosteroids, immunosuppressants, and (plasma exchange [PLEX]), SVV survival rates have considerably improved, from 30 to $75 \%$ at 5 years [3]. The leading causes of death are related mainly to a life-threatening disease at the time of diagnosis or long-term complications of immunosuppressive therapies, all of which may require intensive care unit (ICU) admission [4, 5]. To date, there are only few studies, all retrospective, in which researchers have reported the outcomes of patients with vasculitis admitted to the ICU. The reported ICU mortality rates of the three most recent studies ranged from 11 to $52 \%$ [6-8]. AAV, and particularly granulomatosis with polyangiitis (GPA; Wegener's granulomatosis), was the most frequent form of vasculitis. Unfortunately, all three were single-center studies and heterogeneous in nature, as they included several types of vasculitides with different prognoses. Patients were admitted either in the initial phase of the disease or after a long-term evolution. Finally, therapeutic vasculitis management was poorly described and mostly inhomogeneous between studies.

Nonspecific ICU scores at admission, such as the Simplified Acute Physiology Score II (SAPS II) or Sequential Organ Failure Assessment (SOFA) score, have been reported to be associated with outcome; however, specific vasculitis scores are not adapted to the ICU setting. In light of these circumstances, we carried out a retrospective, multicenter study to describe the clinical course, outcomes, and prognostic factors of patients admitted to the ICU for acute manifestation of new-onset SVV.

\section{Methods}

\section{Study design}

In this retrospective, observational, multicenter study, 22 ICUs in northern France were contacted individually by e-mail on three occasions to analyze the outcomes of patients admitted to the ICU for acute manifestations of
SVV. Two of the centers did not partake in the study. In the 20 participating centers, patients were identified by two methods:

1. We used the computerized registers of each hospital to identify patients with the International Classification of Diseases, Ninth Revision (ICD-9), codes M31.3 for GPA, M30.1 for eosinophilic GPA, M31.7 for microscopic polyangiitis, and N08.5X-005 or $\mathrm{M} 31.0+$ for anti-glomerular basement membrane (GBM) antibody disease.

2. If no patient was found in the computerized database of the medical informatics department, then the following keywords were searched in the hospital report database of each ICU department: "microscopic polyarteritis," "granulomatosis with polyangiitis (or Wegener's)," "eosinophilic granulomatosis with polyangiitis (or Churg-Strauss)," "anti-glomerular basement membrane disease (or Goodpasture syndrome)."

All patients admitted to the ICU for SVV management were screened. When a patient was hospitalized in the ICU on more than one occasion, only the first ICU admission was considered.

\section{Inclusion criteria}

To be included, patients had to fulfill the following criteria:

1. Patients had to be admitted to the ICU for acute manifestations of known or highly suspected SVV (new diagnosis or relapse). On the basis of the results of previously published studies, acute manifestations of known or highly suspected SVV requiring admission in ICU include respiratory failure, acute renal failure, cardiac failure, coma due to central nervous system involvement, and severe gastrointestinal involvement (e.g., peritonitis due to small intestine perforation) $[6,9,10]$.

2. Patients had to receive cyclophosphamide pulse therapy according to French recommendations $[11,12]$ within $48 \mathrm{~h}$ before admission or during their ICU stay.

3. Primary SVV patients were included if they presented with a diagnosis of AAV: microscopic polyarteritis, GPA (formerly known as Wegener's granulomatosis), and eosinophilic GPA (formerly 
known as Churg-Strauss syndrome). Due to similar clinical presentation and initial treatment in the ICU, patients with anti-GBM antibody disease (an immune complex vasculitis formerly known as Goodpasture syndrome) were also included in this study.

\section{Exclusion criteria}

Considering their heterogeneous clinical presentation and management, other immune complex SVV (cryoglobulinemic vasculitis, immunoglobulin A vasculitis, hypocomplementemic urticarial vasculitis [anti-C1q vasculitis]) were excluded from this analysis. Details on SVV not included in the present study are provided in Additional file 1. Patients admitted for an infectious complication secondary to SVV immunosuppressive treatments were excluded from the study.

\section{Data collection}

Each clinical record, in either paper or electronic form, was reviewed at each site by the principal investigator. All scores were calculated by the same principal investigator to ensure interscore reliability. At ICU admission, the following data were collected for each patient: demographic data; reason for admission; medical history; SVV diagnosis type; and disease assessment scores, including SAPS II score, SOFA score, Birmingham Vasculitis Activity Score (BVAS) (version 3), and revised Five-Factor Score (FFS).

SAPS II and SOFA scores were used to assess disease severity. The SAPS II score is calculated using the worst 12 physiological variables during the first $24 \mathrm{~h}$ in the ICU and also includes three disease-related variables [13]. The SOFA score is based on six physiological variables and can be calculated on a daily basis [14].

Vasculitis disease activity was assessed on the basis of the BVAS [15]. This score is based on clinical and biological items in nine separate organ systems: general; cutaneous; mucous membrane and eyes; ear, nose, and throat; cardiovascular; gastrointestinal; pulmonary; renal; and nervous system. The revised FFS was calculated at admission for patients with microscopic polyangiitis, GPA, eosinophilic granulomatosis with polyangiitis, and anti-GBM antibody disease. This score is used to assess prognosis at the time of diagnosis and includes the following items: serum creatinine level $(>150 \mu \mathrm{mol}$ or $<150 \mu \mathrm{mol}$ ); presence of severe gastrointestinal tract involvement; cardiomyopathy; age; and ear, nose, and throat involvement [10].

\section{Study endpoints}

The primary endpoint was assessment of mortality rate 90 days after ICU admission. Outcome was also recorded (survivors and nonsurvivors) in the ICU and at day 90. For each patient, three specific adverse events reflecting global consequences of immunosuppression were recorded during the ICU stay: sepsis, hemorrhagic syndrome, and hematological disorders such as aplasia and thrombopenia. The incidence of these adverse events was collected only if they occurred at least $48 \mathrm{~h}$ after the cyclophosphamide pulse. The duration between the cyclophosphamide pulse and each adverse event was also recorded. Details are provided in Additional file 1.

\section{Ethics}

According to French law (L.1121-1 paragraph 1 and R1121-2, Public Health Code), neither informed consent nor approval of an ethics committee was necessary for anonymous data extraction from and analysis of patients' medical files.

\section{Statistical analysis}

Continuous variables are presented as median and interquartile range, and categorical variables are reported as frequency (percent). Two groups were defined according to 90-day mortality: survivors and nonsurvivors. Comparison between the two groups was performed on continuous variables using Mann-Whitney $U$ tests due to a nonnormal distribution of all variables. For qualitative variables, a $\chi^{2}$ test or Fisher's exact test was used as appropriate. Correlations were assessed using the Pearson correlation test. Association between baseline ICU characteristics with mortality was assessed in univariable and multivariable logistic regression. Given the low number of events, only two explanatory variables could be entered in the multivariable models; that is, several models were constructed, each containing two explanatory variables. These candidate variables entered in multivariable analysis were chosen on the basis of the preceding univariable analysis (entry criteria $p<0.05$ in univariable analysis). Models adjusted for various possible confounders (age, SOFA score at admission, SAPS II at admission) were ultimately presented. Because of the absence of a universally accepted threshold, continuous variables were categorized according to the thresholds identified using the Youden index from receiver operating characteristic curve analyses. Mortality was described using Kaplan-Meier survival estimates and compared between the group baseline characteristics by log-rank tests. All analyses were performed using Prism software (GraphPad Software, La Jolla, CA, USA) and IBM SPSS Statistics 20.0 software (IBM, Armonk, NY, USA). The two-tailed significance level was set at $p<0.05$.

\section{Results}

Population characteristics

The study population characteristics are provided in Table 1 . In the 20 participating centers, 82 patients (36 
Table 1 Baseline demographic characteristics of 82 study patients at admission to ICU

\begin{tabular}{|c|c|}
\hline Characteristics & Data \\
\hline Age, yr & $67.0(63.0-74.5)$ \\
\hline Female sex & $36(44)$ \\
\hline \multicolumn{2}{|l|}{ Medical history } \\
\hline Malignant disease & $5(6)$ \\
\hline Chronic renal failure & $7(8)$ \\
\hline Heart failure & $11(13)$ \\
\hline Chronic respiratory failure & $7(8)$ \\
\hline Neurological failure & $1(1)$ \\
\hline Diabetes & $5(6)$ \\
\hline Malnutrition & $2(2)$ \\
\hline None & $52(63)$ \\
\hline \multicolumn{2}{|l|}{ Performance status ${ }^{a}$} \\
\hline 0: Normal activity & $37(45)$ \\
\hline 1: Symptomatic but completely ambulatory & $41(50)$ \\
\hline 2: Less than $50 \%$ of daytime in bed & $4(5)$ \\
\hline 3: More than $50 \%$ of daytime in bed & $0(0)$ \\
\hline 4: Totally confined to bed or chair & $0(0)$ \\
\hline \multicolumn{2}{|l|}{ Small-vessel vasculitis diseases } \\
\hline Granulomatosis with polyangiitis & $44(54)$ \\
\hline Microscopic polyangiitis & $20(24)$ \\
\hline Eosinophilic granulomatosis with polyangiitis & $5(6)$ \\
\hline $\begin{array}{l}\text { Anti-glomerular basement membrane antibody } \\
\text { disease }\end{array}$ & $13(16)$ \\
\hline \multicolumn{2}{|l|}{ Disease status } \\
\hline Newly or recently diagnosed & $77(94)$ \\
\hline Relapsing disease & $5(6)$ \\
\hline $\begin{array}{l}\text { Patient receiving chronic immunosuppressive } \\
\text { therapy }^{\mathrm{b}}\end{array}$ & $4(5)$ \\
\hline \multicolumn{2}{|l|}{ Cause of admission } \\
\hline Respiratory failure & $28(34)$ \\
\hline Acute renal failure & $24(29)$ \\
\hline Pulmonary-renal failure & $27(33)$ \\
\hline Septic shock & $1(1)$ \\
\hline Others $^{c}$ & $3(4)$ \\
\hline \multicolumn{2}{|l|}{ Disease and severity assessment scores at admission } \\
\hline Simplified Acute Physiology Score II & $37.5(28.0-46.5)$ \\
\hline Sequential Organ Failure Assessment score & $5.0(4.0-8.0)$ \\
\hline Birmingham Vasculitis Activity Score & $16.0(12.0-20.0)$ \\
\hline Revised Five-Factor Score & $2.0(1.0-2.0)$ \\
\hline
\end{tabular}

Data are presented as number (\%) or median (interquartile range)

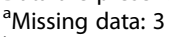

${ }^{\mathrm{b}}$ Missing data: 1

'Two patients with encephalitis and one with myocarditis women, 46 men) with a median age of 67.0 years $(63.0-$ 74.5) were included from January 2001 to December 2014 (Fig. 1). The delay between traditional hospitalization wards and ICU admission was 6.5 days (1-14). Among the study population, 52 patients $(63 \%)$ had no prior medical history and 78 patients $(95 \%)$ had a performance status score of 0 or 1 . Of the included patients, 77 (94\%) were admitted for a new or recent diagnosis of SVV, with GPA (Wegener's) being the main diagnosis (44 patients, $54 \%)$. Thirteen patients (16\%) were admitted to the ICU for an anti-GBM antibody disease. The predominant clinical patterns at admission were pulmonary-renal syndrome (27 patients, $33 \%$ ), isolated respiratory failure (28 patients, $34 \%$ ), and isolated renal failure (24 patients, $29 \%$ ). Reasons for admission for all patients with acute renal failure were indications of renal replacement therapy with the need to pursue PLEX. SAPS II and BVAS at admission were $37.5(28.0-46.5)$ and $16.0(12.0-20.0)$, respectively.

\section{Small-vessel vasculitis and ICU management}

Data for small-vessel vasculitis and ICU management are provided in Table 2. All patients received cyclophosphamide with a median dose of $1000 \mathrm{mg}$ (800-1000). Glucocorticoid pulses were administered in 74 patients (90\%), and 79 patients (96\%) received daily high-dose glucocorticoids. PLEX was performed in 63 patients (77\%). In the ICU, 42 patients $(51 \%)$ required mechanical ventilation during 11.5 days (8.0-22.5) and 25 patients (31 \%) received vasopressor therapy during 7.0 days (3.0-18.5). Renal replacement therapy was performed in 58 patients (71\%) for 13.0 days (8.0-20.75) and was maintained after ICU stay in 28 patients (34 \%).

\section{Adverse events in the ICU}

Data for adverse events in the ICU are given in Table 3. Nine patients $(11 \%)$ presented with neutropenia $<1500 /$ $\mathrm{mm}^{3}$ after the cyclophosphamide pulse, three $(4 \%)$ of whom had a nadir $<500 / \mathrm{mm}^{3}$. Infection was reported in 25 patients (30\%), with the lung being the most frequently infected site (15 patients, $60 \%$ ), predominantly by Gram-negative microorganisms (16 patients, $64 \%$ ). Unfavorable evolution toward septic shock was observed in 13 patients (16\%). Venovenous extracorporeal membrane oxygenation was initiated for refractory respiratory failure in six patients $(7 \%)$, four of whom survived. Lastly, 57 patients $(69 \%)$ presented with at least one hemorrhagic syndrome during their ICU stay. The main cause of death in the ICU was disease flare in $69 \%$ of cases, followed by infection in $31 \%$ of cases.

\section{Comparison between survivors and nonsurvivors at 90 days}

Data derived from comparison of survivors and nonsurvivors at 90 days are provided in Table 4, and the results 


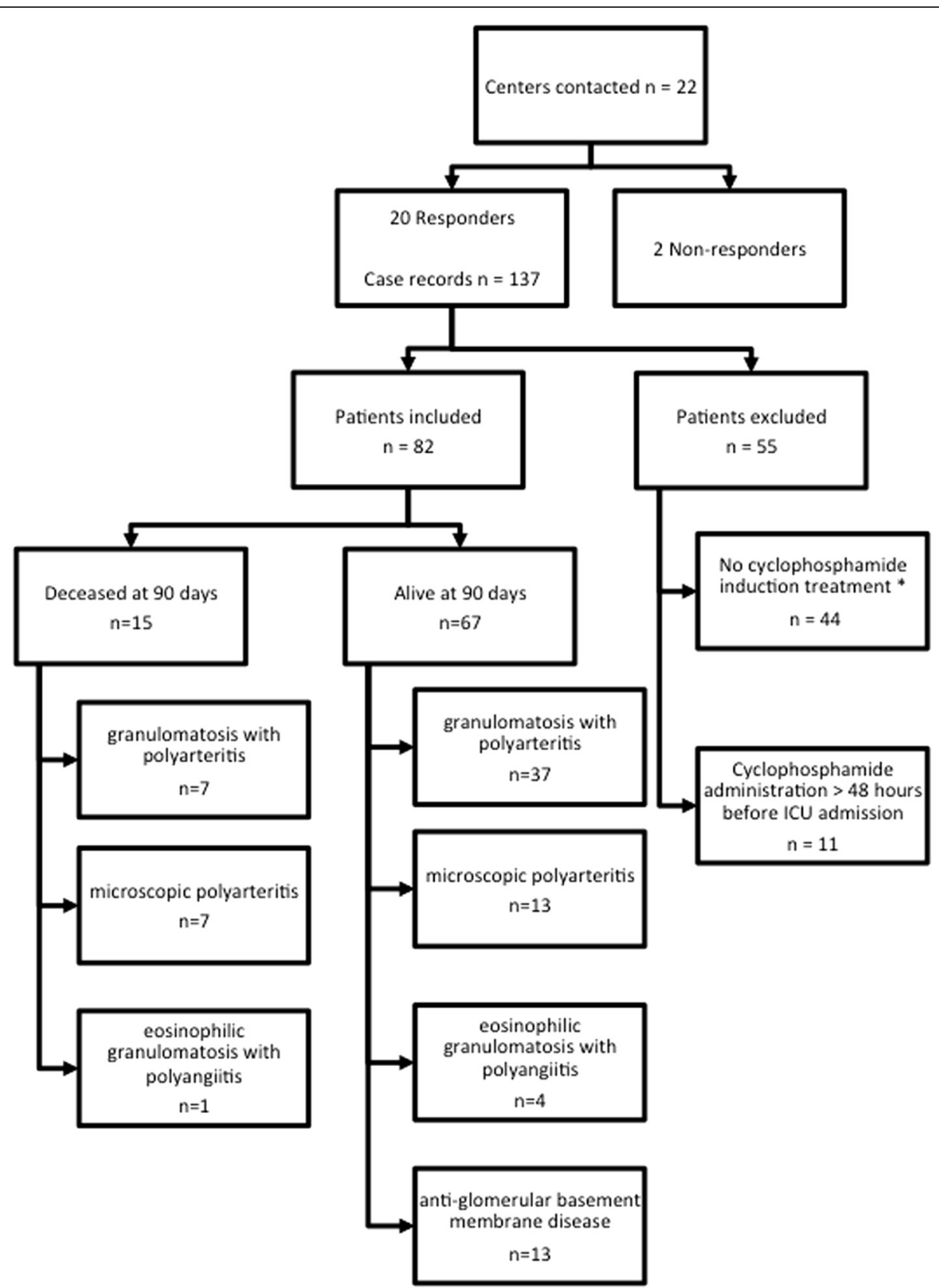

Fig. 1 Flowchart of the included patients with outcome at 90 days, ${ }^{*}$ no patient received rituximab

of univariable and multivariable analyses are given in Table 5.

Overall mortality was $18 \%$ (15 deaths) (Fig. 2). All patients with an anti-GBM disease survived at 90 days. Anti-GBM disease is known to have a better prognosis, which may have lowered the mortality rate. After removing patients with anti-GBM disease and considering only patients with $\mathrm{AAV}$, we found that the mortality rate in the ICU and at 90 days remained less than $20 \%$ and less than $25 \%$, respectively.
Sex, medical history, performance status before ICU admission, vasculitis type, delay between hospitalization ward and ICU admission, reason for admission, induction treatment for SVV, revised FFS, BVAS, and SOFA score at admission were not significantly different between survivors and nonsurvivors.

Nonsurvivors were older than survivors (67 years [62.0$74]$ vs. 58.0 years [40-68], $p=0.003)$. SAPS II score was also significantly higher at ICU admission in nonsurvivors than in survivors $(51$ [38-82] vs. 36 [27-42], $p=0.005)$. A 
Table 2 Small-vessel vasculitis and intensive care management

\begin{tabular}{|c|c|}
\hline & Data $(N=82$ patients $)$ \\
\hline \multicolumn{2}{|l|}{ Small-vessel vasculitis management } \\
\hline $\begin{array}{l}\text { Number of patients receiving glucocorticoid } \\
\text { induction treatment }\end{array}$ & $74(90)$ \\
\hline Number of days & $3.0(3.0-3.0)$ \\
\hline $\begin{array}{l}\text { Total dose, mg methylprednisolone } \\
\text { equivalents }\end{array}$ & $1500(1500-3000)$ \\
\hline $\begin{array}{l}\text { Number of patients receiving daily } \\
\text { glucocorticoids after induction treatment }\end{array}$ & $79(96)$ \\
\hline Number of patients receiving plasma exchange & $63(77)$ \\
\hline Number of sessions & $7.0(5.0-7.0)$ \\
\hline $\begin{array}{l}\text { Number of patients receiving cyclophosphamide } \\
\text { pulse }\end{array}$ & $82(100)$ \\
\hline Induction dose, mg & $1000(800-1000)$ \\
\hline Number of patients receiving rituximab & $3(4)$ \\
\hline \multicolumn{2}{|l|}{ ICU management } \\
\hline $\begin{array}{l}\text { Number of patients receiving mechanical } \\
\text { ventilation }^{\mathrm{a}}\end{array}$ & $42(51)$ \\
\hline Duration of mechanical ventilation, days & $11.5(8.0-22.5)$ \\
\hline $\begin{array}{l}\text { Number of patients receiving venovenous } \\
\text { extracorporeal membrane oxygenation }\end{array}$ & $6(7)$ \\
\hline Number of patients receiving catecholamines & $25(31)$ \\
\hline $\begin{array}{l}\text { Duration of catecholamine administration, } \\
\text { days }\end{array}$ & $7.0(3.0-18.5)$ \\
\hline $\begin{array}{l}\text { Number of patients receiving renal replacement } \\
\text { therapy in ICU }\end{array}$ & $58(71)$ \\
\hline $\begin{array}{l}\text { Duration of renal replacement therapy in ICU, } \\
\text { days }\end{array}$ & $13.0(8.0-20.75)$ \\
\hline $\begin{array}{l}\text { Number of patients receiving renal } \\
\text { replacement therapy before ICU stay }\end{array}$ & $11(13)$ \\
\hline $\begin{array}{l}\text { Number of patients receiving renal } \\
\text { replacement therapy after ICU stay }\end{array}$ & $28(34)$ \\
\hline
\end{tabular}

\section{ICU intensive care unit}

Data are presented as number (\%) or median (interquartile range)

ancluding invasive and noninvasive ventilation

higher SOFA score on the day of cyclophosphamide administration (survivors 6 [3-7] vs. nonsurvivors 11 [612], $p=0.0004$ ), with a threshold value of 8 (sensitivity $73 \%$, specificity $88 \%$ ), was associated with death (Fig. 3). A delayed administration of cyclophosphamide after ICU admission (survivors 2.0 days [1.0-5.0] vs. nonsurvivors 5.0 days [3.0-14.0], $p=0.0053$ ), with a threshold value of 3.5 days (sensitivity $73 \%$, specificity $61 \%$ ), was also associated with unfavorable evolution.

In univariable logistic regression, SOFA score on the day of cyclophosphamide administration and timing between admission and administration of cyclophosphamide were significantly associated with outcome (respectively, odds ratio [OR] with $95 \%$ confidence interval [CI] for a 1-point increase in SOFA score 1.32 [1.13-1.55], $p<0.001$; and for a 1-day increase in delay 1.15 [1.04-1.28]; $p=0.007$ ) (Table 5).
Table 3 Summary of prespecified adverse events recorded in the ICU

\begin{tabular}{|c|c|}
\hline & Data $(N=82$ patients) \\
\hline Neutropenia $^{\mathrm{a}}<1500 / \mathrm{mm}^{3}$ & $9(11)$ \\
\hline $\begin{array}{l}\text { Delay between cyclophosphamide } \\
\text { administration and neutropenia }{ }^{\mathrm{a}}<500 / \mathrm{mm}^{3} \text {, } \\
\text { days }\end{array}$ & $16(2-25)$ \\
\hline Number of patients with infection & $25(30)$ \\
\hline \multicolumn{2}{|l|}{ Location } \\
\hline Urinary tract & $2(8)$ \\
\hline Lung & $15(60)$ \\
\hline Bacteremia & $4(16)$ \\
\hline Others & $4(16)$ \\
\hline \multicolumn{2}{|l|}{ Bacterial source } \\
\hline Gram-positive & $3(12)$ \\
\hline Gram-negative & $16(64)$ \\
\hline Other $^{b}$ & $1(4)$ \\
\hline No pathogen identified & $5(20)$ \\
\hline $\begin{array}{l}\text { Delay between ICU admission and first } \\
\text { infection event, days }\end{array}$ & $13.0(4.5-19.75)$ \\
\hline Number of patients with septic shock & $13(16)$ \\
\hline $\begin{array}{l}\text { Number of patients presenting with } \\
\text { hemorrhagic syndrome }\end{array}$ & $57(69)$ \\
\hline $\begin{array}{l}\text { Number of packed red blood cells infused } \\
\text { during ICU stay }\end{array}$ & $4.0(0-7.5)$ \\
\hline $\begin{array}{l}\text { Delay between ICU admission and first } \\
\text { hemorrhagic event, days }\end{array}$ & $1.0(0-5.0)$ \\
\hline \multicolumn{2}{|l|}{ Cause of death in ICU } \\
\hline Infection & $4(31)$ \\
\hline Disease flare & $9(69)$ \\
\hline
\end{tabular}

ICU intensive care unit

Data are presented as number (\%) or median (interquartile range) a Missing data: 2

${ }^{\mathrm{b}}$ Virus

In multivariable analysis (Table 5), both SOFA score on the day of cyclophosphamide administration and timing between admission and administration of cyclophosphamide were significantly associated with outcome (OR for a 1-day increase in delay 1.16 [95 \% CI 1.05-1.29], $p$ $=0.005$; and OR for a 1-point increase in SOFA 1.35 [1.14-1.60]; $p<0.001)$. All other models identified a significant association for delay between admission and either administration of cyclophosphamide or SOFA score on the day of cyclophosphamide administration, except when adjusted for SAPS II (OR 1.20 [95 \% CI 0.961.48], $p=0.11$ ).

All nonsurvivors received mechanical ventilation and vasopressor therapy (Additional file 2: Table 6).

\section{Discussion}

The main results of the present multicenter study of patients admitted to the ICU with SVV are as follows: (1) 
Table 4 Comparison of survivors and nonsurvivors at 90 days

\begin{tabular}{|c|c|c|c|}
\hline & Survivors $(n=67)$ & Nonsurvivors $(n=15)$ & $p$ Value \\
\hline Age, yr & $58.0(40.0-68.0)$ & $67.0(62.0-74.0)$ & 0.003 \\
\hline Female sex & $30(44)$ & $6(40)$ & 0.78 \\
\hline \multicolumn{4}{|l|}{ Medical history } \\
\hline Malignant disease & $3(4)$ & $2(13)$ & \multirow[t]{8}{*}{0.055} \\
\hline Chronic renal failure & $6(9)$ & $1(6)$ & \\
\hline Chronic respiratory failure & $5(7)$ & $2(13)$ & \\
\hline Heart failure & $6(9)$ & $5(33)$ & \\
\hline Neurological failure & $1(1)$ & $0(0)$ & \\
\hline Diabetes & $3(4)$ & $2(13)$ & \\
\hline Malnutrition & $1(1)$ & $1(6)$ & \\
\hline None & $46(68)$ & $6(40)$ & \\
\hline Performance status ${ }^{a}$ & $2.0(1.0-2.0)$ & $2.0(1.0-2.0)$ & 0.68 \\
\hline \multicolumn{4}{|l|}{ Small-vessel vasculitis diseases } \\
\hline Granulomatosis with polyangiitis & $37(55)$ & $7(47)$ & \multirow[t]{4}{*}{0.06} \\
\hline Microscopic polyangiitis & $13(20)$ & $7(47)$ & \\
\hline Eosinophilic granulomatosis with polyangiitis & $4(5)$ & $1(6)$ & \\
\hline Anti-glomerular basement membrane antibody disease & $13(20)$ & $0(0)$ & \\
\hline Delay between hospitalization ward to admission to ICU, days & $5.0(1.0-12.0)$ & $11.0(2.0-28.0)$ & 0.21 \\
\hline \multicolumn{4}{|l|}{ Reason for admission } \\
\hline Respiratory failure & $1(29)$ & $8(54)$ & \multirow[t]{5}{*}{0.37} \\
\hline Acute renal failure & $22(32)$ & $2(13)$ & \\
\hline Pulmonary-renal failure & $22(32)$ & $5(33)$ & \\
\hline Septic shock & $1(2)$ & $0(0)$ & \\
\hline Others $^{\mathrm{b}}$ & $3(5)$ & $0(0)$ & \\
\hline Number of patients receiving glucocorticoid induction treatment & $62(92)$ & $12(80)$ & 0.15 \\
\hline Number of patients receiving plasma exchange & $50(75)$ & $13(86)$ & 0.50 \\
\hline \multicolumn{4}{|l|}{ Disease and severity assessment scores at admission } \\
\hline Revised Five-Factor Score & $2.0(1.0-2.0)$ & $2.0(1.0-3.0)$ & 0.88 \\
\hline Simplified Acute Physiology Score ॥ & $36(27-42)$ & $51.0(38.0-82.0)$ & 0.005 \\
\hline Sequential Organ Failure Assessment score at admission & $4.0(4.0-7.0)$ & $8.0(6.0-9.0)$ & 0.008 \\
\hline Birmingham Vasculitis Activity Score & $16.0(12.0-20.0)$ & $16.0(12.0-20.0)$ & 0.85 \\
\hline Sequential Organ Failure Assessment score at cyclophosphamide administration & $6.0(3.0-7.0)$ & $11.0(6.0-12.0)$ & 0.0004 \\
\hline Delay between ICU admission and cyclophosphamide administration, days & $2.0(1.0-5.0)$ & $5.0(3.0-14.0)$ & 0.0053 \\
\hline
\end{tabular}

ICU intensive care unit

Data are presented as number (\%) or median (interquartile range)

${ }^{a}$ Missing data: 3

${ }^{\mathrm{b}}$ Two patients with encephalitis and one with myocarditis

mortality represented about one-fifth of the included population, despite life-threatening manifestations at admission requiring aggressive immunosuppressive therapy; (2) subject to other undetected confounding factors that we were not able to include in the multivariable analysis, ICU severity score, such as SOFA score on the day of cyclophosphamide administration in the ICU, also seemed to be associated with unfavorable outcome; and
(3) delayed administration of cyclophosphamide was also likely associated with death.

\section{Causes of ICU admission}

Due to the noninclusion criteria, only one patient presented with septic shock at admission and was diagnosed thereafter with AAV. Consequently, all patients were admitted for acute manifestations of the disease, which 
Table 5 Results of uni- and multivariable analysis

\begin{tabular}{|c|c|c|c|c|}
\hline \multirow[b]{2}{*}{ Model } & \multicolumn{2}{|c|}{$\begin{array}{l}\text { Association between delay from ICU } \\
\text { admission to cyclophosphamide } \\
\text { administration and outcome }\end{array}$} & \multicolumn{2}{|c|}{$\begin{array}{l}\text { Association between SOFA score at } \\
\text { cyclophosphamide administration } \\
\text { and outcome }\end{array}$} \\
\hline & $\mathrm{OR}(\mathrm{Cl})$ & $p$ & $\mathrm{OR}(\mathrm{Cl})$ & $p$ \\
\hline Univariable model & $1.15(1.04-1.28)$ & 0.007 & $1.32(1.13-1.55)$ & $<0.001$ \\
\hline \multicolumn{5}{|l|}{ Multivariable models } \\
\hline Adjusted for age & $1.14(1.03-1.27)$ & 0.01 & $1.33(1.12-1.58)$ & 0.001 \\
\hline Adjusted for SOFA score at admission & $1.16(1.04-1.28)$ & 0.008 & $1.35(1.11-1.64)$ & 0.003 \\
\hline Adjusted for SAPS II at admission & $1.16(1.04-1.29)$ & 0.01 & $1.20(0.96-1.48)$ & 0.11 \\
\hline Adjusted for SOFA score at cyclophosphamide administration & $1.16(1.05-1.29)$ & 0.005 & - & - \\
\hline $\begin{array}{l}\text { Adjusted for delay between ICU admission and cyclophosphamide } \\
\text { administration }\end{array}$ & - & - & $1.35(1.14-1.60)$ & $<0.001$ \\
\hline
\end{tabular}

$\mathrm{Cl}$ confidence interval, ICU intensive care unit, OR odds ratio, SAPS Simplified Acute Physiology Score, SOFA Sequential Organ Failure Assessment Data are presented as odds ratio (95\% confidence interval)

consisted mainly of acute respiratory failure or/and acute renal failure. Overall, respiratory failure was present in two-thirds of our patients. In accordance with this, in the studies of Khan et al. [7] and Monti et al. [16], clinical presentations such as acute respiratory failure related to diffuse intraalveolar hemorrhage were also reported to be the first manifestation of AAV at ICU admission.

\section{Immunosuppressive therapy-related infection in the ICU}

The rate of acquired infection hovered at $30 \%$ and was surprisingly less than that of other populations usually admitted to the ICU [17]. This low rate of infection may be explained by the low exposure of patients to chronic immunosuppressive therapies: Only four patients had been receiving chronic immunosuppressive therapy for more than 6 months before ICU admission. In a retrospective series, Cruz et al. found that patients admitted for an infectious process tended to have a higher mortality

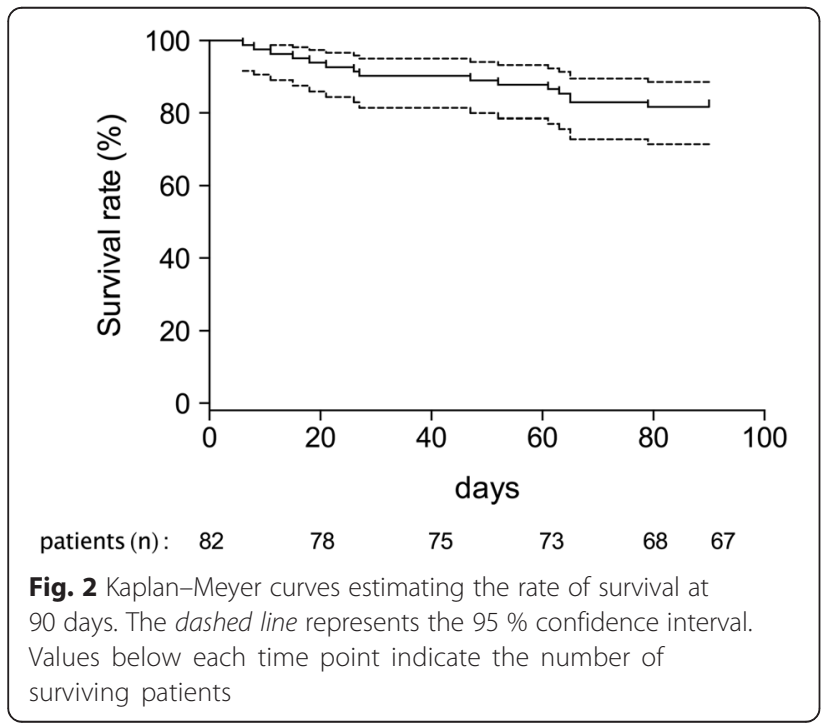

rate [9]. Similarly, Befort et al. recently reported that cause of death was related mainly to an infectious process in $61 \%$ of ICU patients [6]. Prolonged exposure to immunosuppressive therapies such as corticosteroids before ICU admission is also known to be independently associated with a higher risk of death [18]. Conversely, results from the CORTAGE trial confirmed that low cumulative doses of corticosteroids and limited doses of cyclophosphamide at $500 \mathrm{mg}$ per pulse were associated with a lower occurrence of infection in the elderly [19].

Cyclophosphamide has long been the standard induction treatment in acute manifestations of severe AAV. Randomized controlled trials have also shown that rituximab was noninferior to cyclophosphamide therapy for remission induction in these patients [20, 21]. However, the latter study excluded patients with either alveolar hemorrhage sufficiently severe to require mechanical ventilation or with a serum creatinine level greater than $350 \mu \mathrm{mol} / \mathrm{L}$. Patient subset analyses including onefourth of participants with diffuse alveolar hemorrhage or those with major renal disease did not reveal any between-arm differences in remission rate [21]. In these studies, there were no significant differences between the two treatments with respect to adverse events. In the particular setting of the ICU, one can speculate whether rituximab would not be safer than cyclophosphamide for infectious adverse events [22].

It is noteworthy that a high number of our patients were treated with PLEX as an adjunct for frequent acute respiratory failure and/or acute renal failure at patient admission. Patients with respiratory failure due to diffuse alveolar hemorrhage are thought to benefit from PLEX, and the rate of renal recovery in AAV presenting with renal failure has furthermore been shown to be increased with PLEX [23]. The latter is the subject of a large, ongoing, multicenter randomized controlled trial to confirm these data in this patient population (PEXIVAS; ClinicalTrials.gov identifier NCT00987389). 


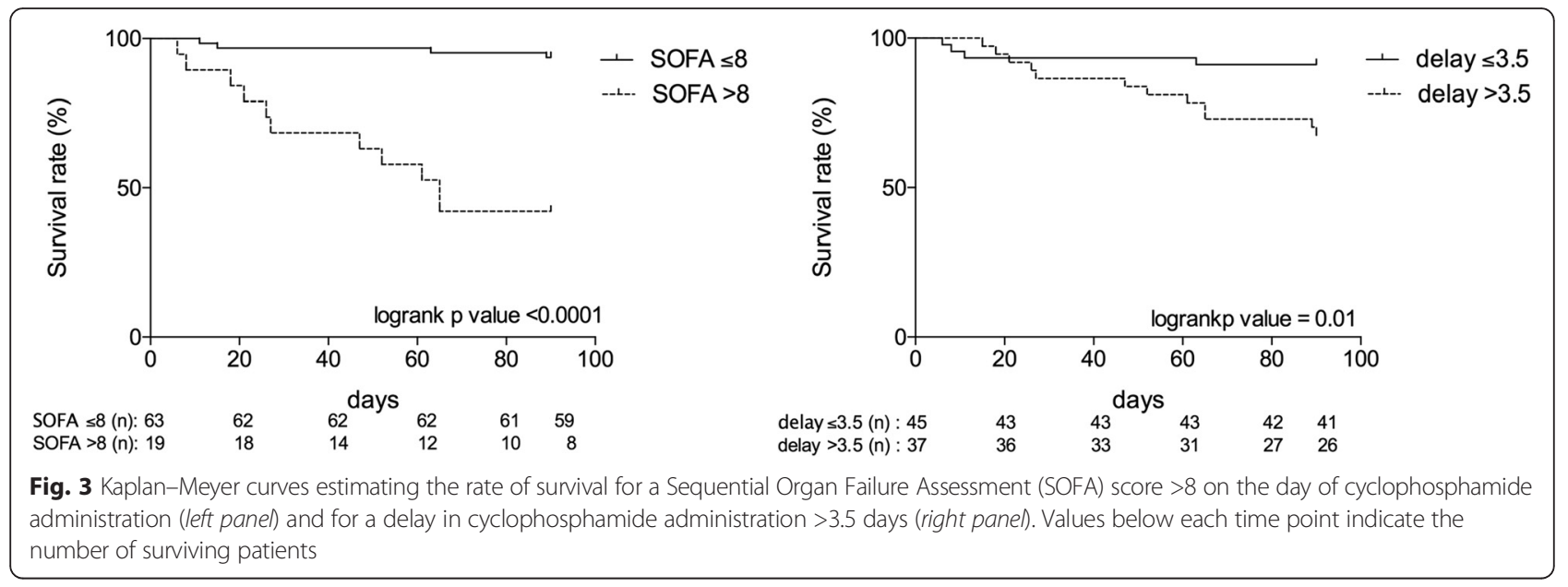

\section{Prognostic factors}

Despite increased use, intensivists do not routinely prescribe immunosuppressive therapies for the management of severe vasculitis. In the ICU, their prescription in instances of multiple organ failure could seem counterintuitive at first glance and most often is associated with an increased complication rate and potentially with a negative outcome. In view of our results, this paradigm appears not to be justified for acute manifestations of SVV. Previous studies have furthermore found highly heterogeneous results with regard to ICU mortality (11$52 \%)$. One major reason may be related to the heterogeneity of the included population. Indeed, most of these studies involved, on one hand, mixed samples including relapse and new diagnoses of various classes of necrotizing vasculitis and, on the other hand, acute manifestations of the disease as well as chronic immunosuppressiverelated infections $[6,7,9,18,24]$. Owing to the high degree of homogeneity of our population, only a small number of factors appeared to be associated with ICU mortality. As expected, a high SAPS II score, which is a nonspecific ICU severity score assessed at admission, was associated with worst outcome. This score was also systematically found to be predictive of ICU mortality in all other previous studies $[6,7,9,18,25]$. In univariable and multivariable analysis, SOFA score measured on the day of cyclophosphamide administration in the ICU was strongly associated with a poorer outcome. The delayed administration of cyclophosphamide in the ICU was also associated with a higher mortality rate. Considering that all patients included in this study presented with an acute manifestation of SVV, it is not surprising that delayed administration of the induction immunosuppressive treatment was associated with death. Similar to the results of the studies of Cruz et al. [9] and Khan et al. [7], BVAS was also a poor predictor of ICU mortality. Indeed, a number of items in this score are a reflection much more of vasculitis activity than of an acute life-threatening manifestation of SVV. Similarly, it was not surprising that FFS was not associated with poor outcome. In the present series, as in others, cardiac symptoms or gastrointestinal involvement, two main criteria included in the FFS, were rare or not found at ICU admission [9].

\section{Study limitations}

The present study is limited by its retrospective nature. Considering the very low incidence rate of SVV with the prespecified inclusion criteria, it would be difficult to conduct a prospective study. Nonetheless, we report a large retrospective analysis of 82 patients at 20 different centers, hence limiting center bias.

Due to the limited number of events recorded in our moderate sample size, we could not adjust for other numerous potential confounders in the multivariable analysis. Adjusting for confounders not identified as significant in this analysis could have weakened the association measured.

It is usual to report the outcome of small-vessel vasculitis at 12 and 60 months because the efficacy of the immunosuppressive therapies can be assessed only after prolonged follow-up. In the present study, we decided to report the outcome only at 90 days for the following reasons. First, the outcome at 90 days represents the specific consequences of ICU stay. Second, with a retrospective multicenter study design, data for longer-term outcomes are most often not fully available.

\section{Conclusions}

Patients admitted to the ICU for life-threatening complications at the initial phase of SVV have an $82 \%$ survival rate. Mortality is positively related to the intensity of organ failure. Delayed immunosuppressant use in the ICU appears to be associated with mortality. Thus, the present study sheds new light on the potential importance of a rapid approach in the treatment of these conditions. 


\section{Key messages}

- Patients admitted to the ICU for acute manifestation of small-vessel vasculitis have an $82 \%$ survival rate.

- Even in the case of multiple organ failure, delayed administration of immunosuppressants is associated with death.

\section{Additional files}

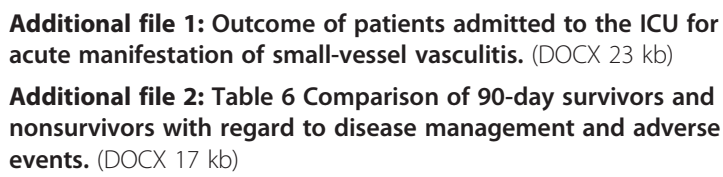

\section{Abbreviations}

AAV: antineutrophil cytoplasmic antibody-associated vasculitis; BVAS: Birmingham Vasculitis Activity Score; Cl: confidence interval; FFS: FiveFactor Score; GBM: glomerular basement membrane; GPA: granulomatosis with polyangiitis; ICD: International Classification of Diseases; ICU: intensive care unit; IQR: interquartile range; OR: odds ratio; PLEX: plasma exchange; SAPS: Simplified Acute Physiology Score; SOFA: Sequential Organ Failure Assessment; SW: small-vessel vasculitides.

\section{Competing interests}

The authors declare that they have no competing interests.

\section{Authors' contributions}

AK and EB acquired the clinical data. NG and NeA performed statistical analysis and interpretation of the clinical data. VD, NT, PT, PA, SE, GG, SG, $\mathrm{NaA}, \mathrm{AD}, \mathrm{ASM}, \mathrm{EA}, \mathrm{JPQ}, \mathrm{JBH}, \mathrm{GL}, \mathrm{RS}, \mathrm{ND}, \mathrm{XP}, \mathrm{DW}$, and $\mathrm{BL}$ drafted the manuscript for important intellectual content. All authors read and approved the final manuscript

\section{Acknowledgements}

We thank Pierre Pothier for editing the manuscript.

\section{Author details}

${ }^{1}$ Brabois Medical Intensive Care Unit, Nancy University Hospital, Vandoeuvre-les-Nancy, Nancy 54000, France. ${ }^{2}$ INSERM U1116, Vandoeuvre-les-Nancy, Nancy, France. ${ }^{3}$ Medical-Surgical Intensive Care Unit, Andre Gregoire District Hospital Center, Montreuil F-93105, France. ${ }^{4}$ Medical Intensive Care Unit, Caen University Hospital, Avenue de la Côte de Nacre, 14000 Caen, France. ${ }^{5}$ Medical Intensive Care Unit, Angers University Hospital, Angers F-49933, France. ${ }^{6}$ Medical Intensive Care Unit, Bretonneau University Hospital, Tours F-37044, France. ${ }^{7}$ Medical Intensive Care Unit, Cochin University Hospital, Paris F-75014, France. ${ }^{8}$ Medical Intensive Care Unit, Rouen University Hospital, Rouen 76031, France. ${ }^{9}$ Medical Intensive Care Unit, Kremlin-Bicêtre University Hospital, Paris F-94275, France. ${ }^{10}$ Medical Intensive Care Unit and Respiratory Division, Pitié-Salpêtrière University Hospital, Paris 75013, France. ${ }^{11}$ Medical-Surgical Intensive Care Unit, Lille University Hospital, Lille F-59000, France. ${ }^{12}$ Medical Intensive Care Unit, Saint-Louis University Hospital, Paris 75010, France. ${ }^{13}$ Medical Intensive Care Unit, Dijon University Hospital, Dijon F-21079, France. ${ }^{14}$ Medical Intensive Care Unit, NHC University Hospital, Strasbourg F-67091, France. ${ }^{15}$ Medical Intensive Care Unit, Mercy Regional Hospital, Ars-Laquenexy 57530, France. ${ }^{16}$ Medical Intensive Care Unit, Bichat - Claude-Bernard University Hospital, Paris 75018, France. ${ }^{17}$ INSERM CIC 1433, Nancy University Hospital, Nancy 54000, France. ${ }^{18}$ INSERM CIC-EC, CIE6, Nancy University Hospital, Nancy 54000, France. ${ }^{19}$ Vascular Medicine Division and Regional Competence Center for Rare Vascular and Systemic Autoimmune Diseases, Nancy University Hospital, Vandoeuvre-les Nancy, Nancy 54511, France. ${ }^{20}$ National Referral Center for Necrotizing Vasculitides and Systemic Sclerosis, Cochin Hospital, University Paris Descartes, Paris F-75014, France.
Received: 2 October 2015 Accepted: 14 January 2016

Published online: 26 January 2016

\section{References}

1. Jennette JC, Falk RJ, Bacon PA, Basu N, Cid MC, Ferrario F, et al. 2012 revised International Chapel Hill Consensus Conference Nomenclature of Vasculitides. Arthritis Rheum. 2013;65:1-11.

2. Mahr A, Guillevin L, Poissonnet M, Aymé S. Prevalences of polyarteritis nodosa, microscopic polyangiitis, Wegener's granulomatosis, and ChurgStrauss syndrome in a French urban multiethnic population in 2000: a capture-recapture estimate. Arthritis Rheum. 2004;51:92-9.

3. Phillip R, Luqmani R. Mortality in systemic vasculitis: a systematic review. Clin Exp Rheumatol. 2008;26(5 Suppl 51):S94-104.

4. Semple D, Keogh J, Forni L, Venn R. Clinical review: Vasculitis on the intensive care unit - part 2: treatment and prognosis. Crit Care. 2005;9:193-7.

5. Holguin F, Ramadan B, Gal AA, Roman J. Prognostic factors for hospital mortality and ICU admission in patients with ANCA-related pulmonary vasculitis. Am J Med Sci. 2008;336:321-6.

6. Befort $\mathrm{P}$, Corne $\mathrm{P}$, Filleron $\mathrm{T}$, Jung $\mathrm{B}$, Bengler $\mathrm{C}$, Jonquet $\mathrm{O}$, et al. Prognosis and ICU outcome of systemic vasculitis. BMC Anesthesiol. 2013;13:27.

7. Khan SA, Subla MR, Behl D, Specks U, Afessa B. Outcome of patients with small-vessel vasculitis admitted to a medical ICU. Chest. 2007;131:972-6.

8. Moreels M, Melot C, Leeman M. Prognosis of patients with systemic rheumatic diseases admitted to the intensive care unit. Intensive Care Med. 2005;31:591-3

9. Cruz BA, Ramanoelina J, Mahr A, Cohen P, Mouthon L, Cohen Y, et al. Prognosis and outcome of 26 patients with systemic necrotizing vasculitis admitted to the intensive care unit. Rheumatology (Oxford). 2003:42:1183-8.

10. Guillevin L, Pagnoux C, Seror R, Mahr A, Mouthon L, Le Toumelin P, et al. The Five-Factor Score revisited: assessment of prognoses of systemic necrotizing vasculitides based on the French Vasculitis Study Group (FVSG) cohort. Medicine (Baltimore). 2011;90:19-27.

11. Charles P, Bienvenu B, Bonnotte B, Gobert P, Godmer P, Hachulla É, et al. Rituximab: recommendations of the French Vasculitis Study Group (FVSG) for induction and maintenance treatments of adult, antineutrophil cytoplasm antibody-associated necrotizing vasculitides. Presse Med. 2013;42: 1317-30.

12. Groupe Français d'Étude des Vascularites (GFEV). Schéma d'administration du cyclophosphamide pour les vascularites systémiques [in French]. http:// www.vascularites.org/schema-d-administration/. Accessed 20 January 2016.

13. Le Gall JR, Lemeshow S, Saulnier F. A new Simplified Acute Physiology Score (SAPS II) based on a European/North American multicenter study. JAMA. 1993;270:2957-63.

14. Vincent JL, Moreno R, Takala J, Willatts S, De Mendonça A, Bruining H, et al. The SOFA (Sepsis-related Organ Failure Assessment) score to describe organ dysfunction/failure. Intensive Care Med. 1996;22:707-10.

15. Mukhtyar C, Lee R, Brown D, Carruthers D, Dasgupta B, Dubey S, et al. Modification and validation of the Birmingham Vasculitis Activity Score (version 3). Ann Rheum Dis. 2009;68:1827-32.

16. Monti S, Montecucco C, Pieropan S, Mojoli F, Braschi A, Caporali R. Lifethreatening onset of systemic vasculitis requiring intensive care unit admission: a case series. Clin Exp Rheumatol. 2015;33:126-31.

17. Vincent JL, Rello J, Marshall J, Silva E, Anzueto A, Martin CD, et al. International study of the prevalence and outcomes of infection in intensive care units. JAMA. 2009;302:2323-9.

18. Godeau B, Mortier E, Roy PM, Chevret S, Bouachour G, Schlemmer B, et al. Short and longterm outcomes for patients with systemic rheumatic diseases admitted to intensive care units: a prognostic study of 181 patients. J Rheumatol. 1997;24:1317-23.

19. Pagnoux C, Quéméneur T, Ninet J, Diot E, Kyndt X, de Wazières B, et al. Treatment of systemic necrotizing vasculitides in patients aged sixty-five years or older: results of a multicenter, open-label, randomized controlled trial of corticosteroid and cyclophosphamide-based induction therapy. Arthritis Rheumatol. 2015;67:1117-27.

20. Jones RB, Tervaert JW, Hauser T, Luqmani R, Morgan MD, Peh CA, et al. Rituximab versus cyclophosphamide in ANCA-associated renal vasculitis. N Engl J Med. 2010;363:211-20.

21. Stone JH, Merkel PA, Spiera R, Seo P, Langford CA, Hoffman GS, et al. Rituximab versus cyclophosphamide for ANCA-associated vasculitis. N Engl J Med. 2010;363:221-32 
22. Specks U, Kronbichler A, Jayne DR. Pro: Should all patients with anti-neutrophil cytoplasmic antibody-associated vasculitis be primarily treated with rituximab? Nephrol Dial Transplant. 2015;30:1083-7.

23. Jayne DR, Gaskin G, Rasmussen N, Abramowicz D, Ferrario F, Guillevin L, et al. Randomized trial of plasma exchange or high-dosage methylprednisolone as adjunctive therapy for severe renal vasculitis. J Am Soc Nephrol. 2007;18:2180-8.

24. Frausova D, Brejnikova M, Hruskova Z, Rihova Z, Tesar V. Outcome of thirty patients with ANCA-associated renal vasculitis admitted to the intensive care unit. Ren Fail. 2008;30:890-5.

25. Hruskova Z, Casian AL, Konopasek P, Svobodova B, Frausova D, Lanska V, et al. Long-term outcome of severe alveolar haemorrhage in ANCA-associated vasculitis: a retrospective cohort study. Scand J Rheumatol. 2013;42:211-4.

Submit your next manuscript to BioMed Central and we will help you at every step:

- We accept pre-submission inquiries

- Our selector tool helps you to find the most relevant journal

- We provide round the clock customer support

- Convenient online submission

- Thorough peer review

- Inclusion in PubMed and all major indexing services

- Maximum visibility for your research

Submit your manuscript at www.biomedcentral.com/submit
Biomed Central 